\title{
Patients' Experiences of Pain Following Day Surgery - At 48 Hours, Seven Days and Three Months
}

\author{
Helena Inger Rosén", Ingrid Helena Bergh, Anders Odén and Lena Birgitta Mårtensson
}

School of Life Sciences, University of Skövde, Box 408, Skövde, (SE-541 28), Sweden

\begin{abstract}
Recent studies indicate that patients experience pain after day surgery for a longer period than previously known. This requires verification. This was a prospective, descriptive correlational study. A convenience sample of 298 day surgery patients undergoing various surgical procedures was asked to report pain intensity and its interference with daily function 48 hours, seven days and three months after day surgery. Correlation and regression analyses were performed. On a NRS, 55\% $(n=230)$ reported pain $(\geq 4) 48$ hours after surgery, as did $43 \%(n=213)$ at seven days. Pain interfered with normal activities at $\geq 4$ NRS at 48 hours and at seven days, after which it decreased.
\end{abstract}

Keywords: Pain, day surgery, recovery, normal activities, daily function.

\section{OVERVIEW}

Postoperative pain following day-surgery and its interference with the ability to return to normal activity lasts for a longer period than previously known [1]. These findings need to be further explored, since in the industrialized world, most elective operations, up to $70 \%$ are now performed as day surgery [2]. Clinicians may assume that the recovery period at home after day surgery, including patients' experience of pain, is relatively harmless and uneventful. This study described patients' perception of pain, return to normal activities and daily function over time after day surgery.

It is already known that: pain duration after day surgery is more prolonged than anticipated, i.e. from several days up to one month [3], pain interferes with daily function in an older population the first three days after day surgery [4] and patients' pain interferes with work, general activities and walking ability during the first days, up to a week, after day surgery [5]. However, knowledge of the patients' pain experience during the recovery period beyond one month remains almost nonexistent. This knowledge is essential for the perioperative nurses in order to optimise performance and provide care for patients undergoing day surgery. Furthermore, it indicates a need for perioperative nurses to continuously update their knowledge and insight into the patients' situation, including the pain associated with day surgery, and thereby hopefully increase their ability to provide personalized follow-up when necessary.

\section{BACKGROUND}

There is international consensus that moderate to severe pain follows day surgery, as reported in studies from the USA [6, 7], Canada [8], Europe [9, 10] Asia [11] and Africa [12]. Despite extensive research in the area of day surgery,

*Address correspondence to this author at the School of Life Sciences, University of Skövde, Box 408, Skövde, (SE-541 28), Sweden; Tel: +46 500 448447; Fax: +46 500 448498; E-mail: helena.rosen@his.se there is still an insufficient number of studies regarding patients' experience of pain, especially over time $[1,9]$.

Despite an increased focus on pain and the development of new standards of postoperative pain management, pain remains as the most prominent symptom following day surgery $[13,14]$. Pain after day surgery is reported mainly during the first week, according to results found with different categories of patients who underwent different types of surgery. In some cases, pain continues to be severe up to one month postoperatively [1]. There is probably no difference between the patient's pain experience following day surgery and that following inpatient surgery [15]. However, while inpatients receive professional care in the hospital, day surgery patients are advised and expected to have a physically able adult who can care for them for 24 hours after discharge. The patient and/or caregiver is presumed to be responsible for care, including pain relief [16]. Furthermore, this 24-hour period is not necessarily sufficient, due to difficulties in managing pain at home [17]. The use of analgesics has been described as low after discharge, despite reported pain, due to factors such as ignorance of the importance of relieving acute pain, regular medication administration or to fear of addiction [18]. This constitutes a threat to health, as unrelieved pain may contribute to complications such as the risk of developing long-term pain [19]. Pain usually decreases over time, but may remain severe enough to interfere with daily function in some cases. Experience of pain at discharge is an unreliable predictor of pain during the recovery period [7]. Moreover, the recovery period required to regain normal function can last several days [20] or even up to six month after surgery [21]. It is, however, difficult to manage pain and its interference with daily functions, as long as there is lack of knowledge about the trajectory of the pain experience following day surgery. It is therefore important to investigate patients' pain experiences following day surgery at multiple time-points.

The Symptom Management Theory (SMT) [22] has been used loosely as the framework in this study. This theory was developed to meet the need for a generic symptom 
management theory for directing care and research on a variety of symptoms which result from from a variety of diseases and conditions. The theory is based on the interrelatedness of three dimensions: symptom experience, symptom management strategies and outcomes; which are necessary to effectively manage any given symptom or group of symptoms (Fig. 1). Each of these dimensions consists of sub-concepts, for example perception, evaluation and response, within the dimension of symptom experience. The domains; person, environment and health \& illness are conceptualised as contextual variables influencing symptom management. The theory is based on assumptions that highlight the importance of taking the patient's perceptions into account when studying symptoms.

From this perspective, awareness of pain as a multidimensional subjective experience, dynamic and interacting with the patient's perceptions, is important in order to understand an individual's pain reaction [22]. The three parallel dimensions; affective/motivational, sensory/ discriminative and cognitive/evaluative, all contribute to influencing the patient's individual perception of pain [23]. The affective/motivational dimension is notable for instance, in connection with patients' previous experiences of day surgery which have been reported to impact their pain at the next occasion of day surgery. This suggests that previous experiences of pain may affect pain perception [24]. The sensory/discriminative dimension underlies the patient's ability to describe pain in terms of intensity, duration and location [25]. Cognitive/evaluative dimensions are associated with factors such as mood, behavior and thought patterns $[26,27]$ and relate to the difference between the sensory dimensions of pain, i.e. intensity or severity, and the reactive dimension of pain, i.e. interference with daily function. Certain aspects of pain's impact on daily function in an older population up to the third evening following discharge, such as general activity, mood, walking ability, normal work, relations, sleep and enjoyment of life, were described by Kemper [4]. However, according to our best knowledge, there is a lack of research into how pain interferes with daily life over time in a more general aged population.

Pain experiences are defined as patients' self-reports of the pain 48 hours, seven days and three months following day surgery. Worst pain refers in the present paper to the patients' report on a numerical rating scale, NRS, (0-10, where $0=$ no pain and $10=$ worst imaginable pain). Normal activities are defined as activity/work at home or gainful employment. Daily function is defined as general activity, walking, working, sleep, mood, enjoyment of life and relations with others. Return to normal activity refers to the ability to return to the activities defined above. The following research questions were asked: What is the proportion of patients with worst pain NRS $\geq 4$ following day surgery? How does pain interfere with daily function and daily life following day surgery? What is the relationship between the worst experienced pain at 48 hours and return to normal activity within seven days? What is the relationship between the pain's interference with normal activity at 48 hours and return to normal activity within seven days following day surgery? and What is the relationship between

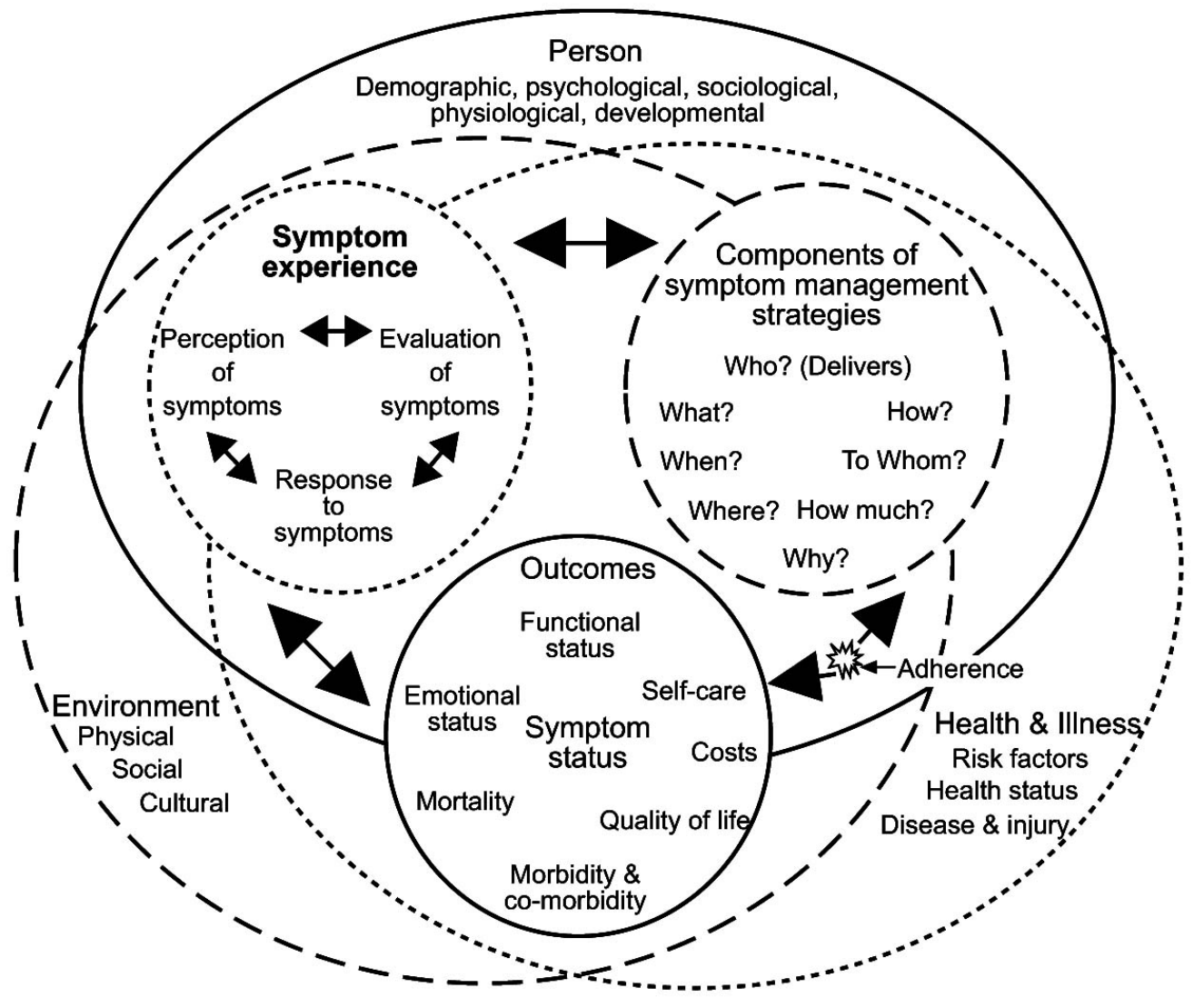

Fig. (1). Revised Symptom Management Conceptual Model. Dodd et al., (2001) Advancing the science of Symptom Management Journal of Advanced Nursing, 33(5), p. 670. Permission is granted in a letter from John Wiley \& Sons Ltd 090210. 
worst experienced pain at 48 hours following day surgery and returning to normal activity within seven days and the? The aim of this study is to describe patients' perception of pain, their return to normal activities and their daily function over time, following day surgery.

\section{APPROACH AND METHODOLOGY}

A prospective, descriptive correlational, study was used to survey 298 patients undergoing a variety of day surgery procedures in a 450-bed community hospital in Sweden. Questionnaires were presented at three time-points: 48 hours, seven days and three months after day surgery.

\section{Sample and Recruitment}

The study was carried out over one year at a day surgery unit, at which 3,300 day surgery procedures are carried out annually. We planned for a $20 \%$ attrition rate over time and aimed at achieving a reasonably-sized sample of patients experiencing moderate to severe pain. Based on reports in the literature, a numerical rating scale (NRS) pain score of $\geq 4$ is a cut-off point, distinguishing patients who experienced substantial pain from those who did not [5]. We assumed that approximately $60 \%$ of the patients would report pain intensity $\geq 4$ on the NRS during the first 48 hours. The inclusion criteria were: 1) age 18 and above, 2) able to read and write Swedish and 3) day surgery patient at the department of orthopedics, general surgery or urology. Due to the inclusion criteria, 435 patients were asked to participate in the study. Participation in the study was requested via a letter attached to the confirmation letter for their surgery. Preoperative assessment was primarily a clinical process with additional tests performed only when specifically required. The unit's standard basal analgesia treatment, 1 gram of acetaminophen, was given to all patients preoperatively and postoperatively. The choice of anesthesia and postoperative pain treatment was left to the individual anesthesiologist. Discharge criteria included stable vital signs, Visual Analogue Scale (VAS) pain score $\leq 4$ and no nausea, vomiting or dizziness, as well as the ability to void urine.

\section{Data Collection and Measures}

After written informed consent, the patient received an envelope on admission to the day surgery unit. The envelope contained written information about the study and questionnaires which were to be answered at 48 hours and seven days, after surgery, postage-paid envelopes included. Details of the response rate at the different time points (T1 i.e. 48 hours, $\mathrm{T} 2$ i.e. seven days and $\mathrm{T} 3$ i.e. three months) are given in Fig. (2). The questionnaires to be answered three months following surgery were sent by postal mail and postage-paid envelopes were included. All participants were informed that the questions in the questionnaires referred to surgery-related pain. If it had not already been answered, the patients were called up after four days and reminded to answer T1. The second reminder of T1 was given over the telephone nine days after surgery when the first reminder for T2 was given. The second reminder was given for T2 over the telephone 14 days after surgery. Postage-paid envelopes with reminders were sent to those patients who did not answer T3 within two weeks and, if required, a second reminder was sent within another two weeks. However, if the patients did not respond within this period they were excluded from the study.

\section{Assessment Instrument}

The Swedish version of the Brief Pain Inventory Short Form (BPI-SF) [28, 29] was used in this study with permission (personal communication, C.S. Cleeland, July 2006). BPI- SF allows the patient to score intensity of pain and its interference with daily function (i.e. interference with general activity, mood, walking ability, normal work, relations, sleep and enjoyment of life) on NRS. The instrument assesses pain intensity on a NRS $(0-10$, where $0=$ no pain and $10=$ worst imaginable pain), as well as pain locations, pain descriptors, pain treatment, relief obtained and pain interference with daily function (NRS 0-10, where $0=$ does not interfere and $10=$ completely interferes). Demographic data such as gender and age are also included. Furthermore, the BPI-SF was supplemented with an additional, "yes or no", question: "Were you able to return to normal activity (includes both activity/work outside the home and at home, for example housework) after surgery? Mark the most correct alternative in your case." This question has also been used in other studies [20, 30-32].

\section{Validity and Reliability}

The BPI-SF has shown both good criterion validity and internal consistency [33]. The instrument is reliable [33] (Crohnbach $\alpha 0.86$ ) and has been used extensively in clinical studies [34-36]. An estimate of the measurement reliability for BPI-SF in a Norwegian study resulted in Chronbach's alpha 0.87 for pain severity and 0.92 for the inference scales in the instrument [37]. The corresponding values in the present study were: 0.89 for pain severity and 0.89 for the inference scales. In the present paper, "worst pain" refers to the patients' report on the instrument BPI-SF, "pain at its worst" (0-10) in the last 24 hours. The item "pain at its worst in the last 24 hours" in the BPI (also included in BPI-SF), has been found to fulfill the measurement properties in terms of reliability and construct validity [38]. The content validity of the additional question was established by a panel of postoperative pain assessment experts and tested in a pilot study with ten patients, after which minor clarifications were made.

\section{Ethical Considerations}

The study was approved by the regional Ethics Committee in Gothenburg. Written informed consent was obtained from each participant. The invitation letter sent to the patients emphasised confidentiality, the fact that participants could withdraw from the study at any time without giving a reason and that withdrawal would not affect their current or future care in any way.

\section{Data Analysis and Results}

The data were analyzed using SPSS version 14 for Windows and non-commercially available programs for Pitman's test [39, 40]. To assess the reliability of the Swedish version of the BPI-SF, alpha coefficients were computed for the four severity items and the seven interference items in the instrument. The questions in focus were the proportion of patients with worst pain, i.e. NRS $\geq 4$, and pain's interference with daily function and life following 


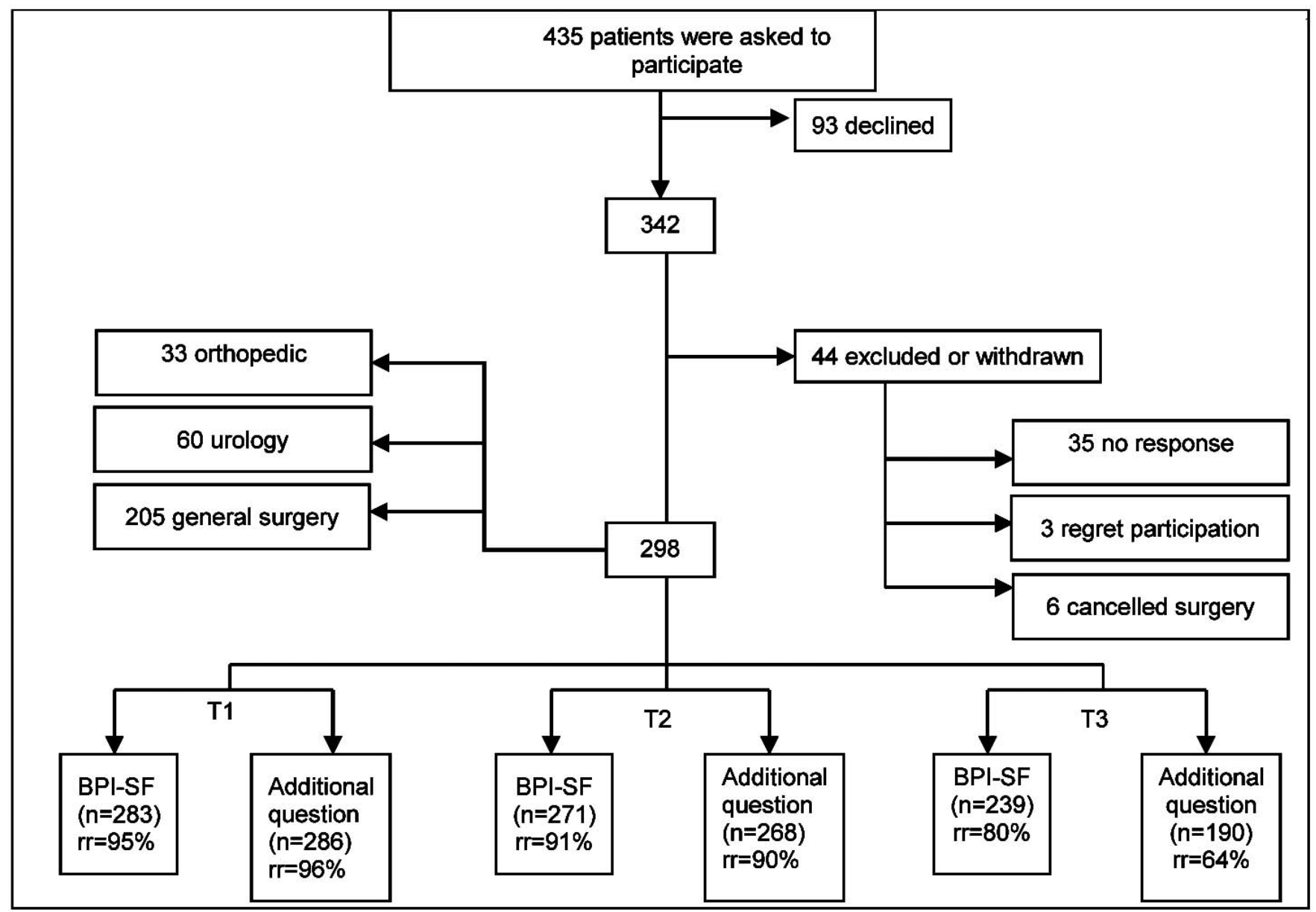

Fig. (2). Flow chart for participation throughout the study $(\mathrm{T} 1=48$ hours after day surgery; $\mathrm{T} 2=$ seven days after day surgery; $\mathrm{T} 3=\mathrm{three}$ months after day surgery; BPI-SF=Brief Pain Inventory Short Form with the respective endpoints $0=$ no pain and $10=$ worst imaginable pain and $0=$ does not Interfere and $10=$ completely interferes; additional question=the additional question about return to normal function; $\mathrm{rr}=$ response rate)

day surgery. A comparison of patients reporting NRS $\geq 4$ at seven days with those reporting NRS $<4$ at three months, concerning NRS at seven days was calculated, using a t-test. Descriptive, inferential, correlation and regression analyses were performed at 48 hours and seven days after surgery. Data analysis focused on the proportion of worst pain during the last 24 hours. The probability of worst pain being $\geq 4$ on NRS was estimated and exact confidence intervals were calculated. The correlations between each of the variables, as well as the correlations between return to normal activity and the variables worst experienced pain and pain's interference with normal activity, were tested with Pitman's test [40], a non-parametric test based on original values, but not on ranks, in contrast to the better-known Spearman's test. Logistic regression analyses were undertaken to identify predictors of returning to normal activity. The area under the ROC curve was determined in order to ascertain the certainty of the prediction [41].

In total, 298 patients were included in the study. The response rate was $69 \%(n=298)$ of those who were asked to participate $(n=435)$ in the study. The study participants were equally divided in terms of gender (male $49 \%$ and female $51 \%$ ) and they ranged in age from 18 to 88 (mean 54). The majority of the patients responded to both the BPI-SF and to the additional question (Fig. 2).

Fifty five percent $(n=127)$ of the patients rated their worst pain experiences $\geq 4$ on the NRS $(0-10)$ at 48 hours, as well as $43 \%(n=91)$ at seven days and $34 \%(n=26) \%$ at three months after surgery, of those patients who responded (Table 1). As Table 1 shows, those patient who reported pain $\geq 4$ (NRS) at 7 days also reported pain $\geq 4$ (NRS) at 3 months to a higher extent $(\mathrm{p}<0.001, \mathrm{t}$-test) than those who reported pain $<4$ (NRS) at seven days.

At 48 hours $93 \%(n=220)$ patients reported using some kind of pain medication, most often paracetamol (acetaminophen) in combination with diclofenac, with additional oral morphine in a few cases. At seven days $72 \%$ $(n=189)$ reported using some kind of medication and at three months $51 \%(n=57)$ used the same medication combinations as at 48 hours; however, no-one used morphine. At 48 hours following surgery 94 patients denied suffering pain during the preceding week. On the other hand $36 \%(n=34)$ of those, continued to rate pain in the BPI-SF, despite having denied pain.

The reactive dimension of pain, interference, scored as the mean of the seven interference items, was calculated. At 
Table 1. Proportion of Patients with Worst Pain NRS $\geq 4$ (Defined Cut-Off)

\begin{tabular}{|c|c|c|c|c|}
\hline \multirow{2}{*}{ Time-Point } & \multicolumn{2}{|c|}{ Number of Patients } & \multirow{2}{*}{ Proportion (95\% CI) } \\
\cline { 2 - 5 } & Worst Pain $<\mathbf{4}$ & Worst Pain $\geq \mathbf{4}$ & P \\
\hline \hline 48 hours $(\mathrm{n}=230)$ & 103 & 127 & $0.55(0.49-0.62)$ & $0.43(0.36-0.50)$ \\
\hline 7 days $(\mathrm{n}=213)$ & 122 & 91 & $0.34(0.24-0.46)$ & $0.001 \#$ \\
\hline 3 months $(\mathrm{n}=76)$ & 50 & 26 & \\
\hline
\end{tabular}

NRS=Numerical Rating Scale; values are given as $\mathrm{n}$; \# Comparison of patients reporting NRS $\geq 4$ at 7 days with those reporting NRS $<4$ at 3 months, concerning NRS at 7 days, $t$ test. The difference was significant, $\mathrm{p}<0.001$.

48 hours after day surgery, interference was 3.9 ( $\mathrm{SD} \pm 2.43$ ) $(\mathrm{n}=235)$ on the NRS. However, interference subsided over time and at seven days it had decreased to $2.84(\mathrm{SD} \pm 2.51)$ $(n=216)$. Pain particularly affected the variables "general activity", "normal work" and the "ability to walk". Pain interfered at NRS $>4$ with work at 48 hours and seven days, after which it subsided, although it was still reported three months after surgery (Fig. 3).

There was a significant correlation between worst pain at 48 hours and return to normal activity within seven days $(\mathrm{p}<0.001)$, Pitman's test [39]. There was also a significant correlation between interference at 48 hours and return to normal activity within seven days $(\mathrm{p}<0.001$, Pitman's test) [39]. If worst pain at 48 hours was used as a predictor of return to work at seven days or previously, we obtained an area under the ROC curve of 0.642. Fig. (4) shows a prediction of return to normal activity performed by applying logistic regression and spline functions.

Logistic regression is a useful way of describing the relative risk with one or more risk factors e.g. pain and an outcome such as not being back to work seven days following surgery, which only has two possible values: back or not back (Good 2000). Sixty-five percent $(n=187)$ of the patients $(n=286)$ had not returned to normal activity at 48 hours following day surgery. At seven days $49 \%(n=132)$ of patients $(n=268)$ had still not returned; the corresponding figure after three months was $13 \%(n=25)$ out of patients $(n=190)$.

Table 2 illustrates the probability of patients' returning to normal activity at seven days. The area under the ROC curve for the predictor $\mathrm{z}(=-0.3146$ the variable interference with work at 48 hours - 1.6034 - the variable returned to normal activity at 48 hours) was 0.837 , which enables a credible
General Activity

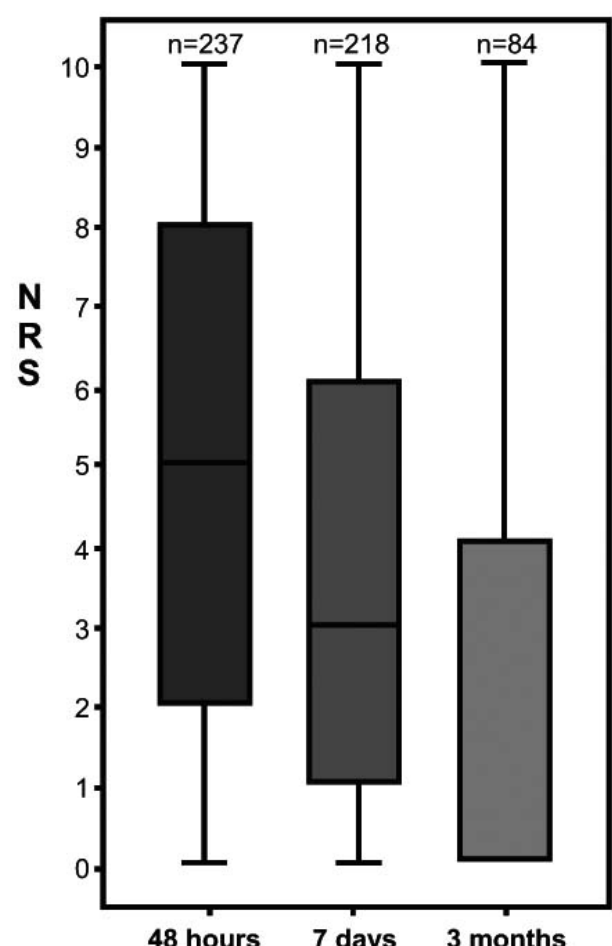

Walking

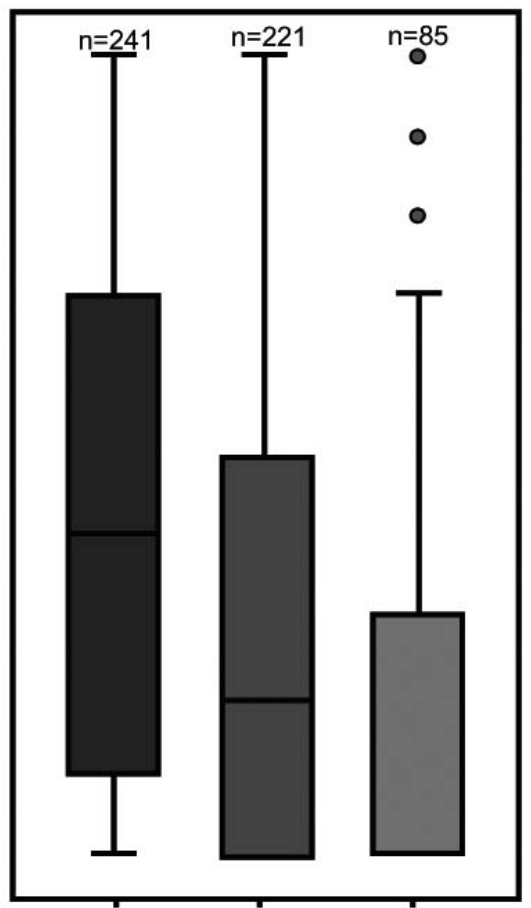

48 hours 7 days 3 months

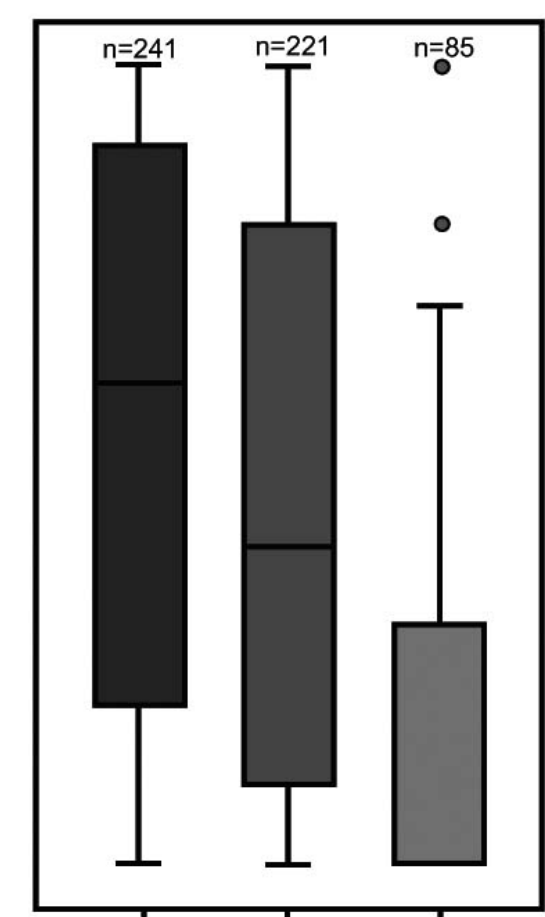

48 hours 7 days 3 months

Time-point

Fig. (3). Pain's interference with; normal work, walking and general activity during the preceding 24 hours, at three time-points after day surgery $(\mathrm{NRS}=$ Numerical rating scale with the endpoints $0=$ does not interfere and $10=$ completely interferes). 
prediction concerning whether patients will be returned to normal activity on day seven or earlier, on the basis of the variables at 48 hours (Table 2). The area under the ROC curve equals the probability that the predictor $\mathrm{z}$ reaches a higher value for a randomly chosen patient who returns to work, compared with a patient who does not.

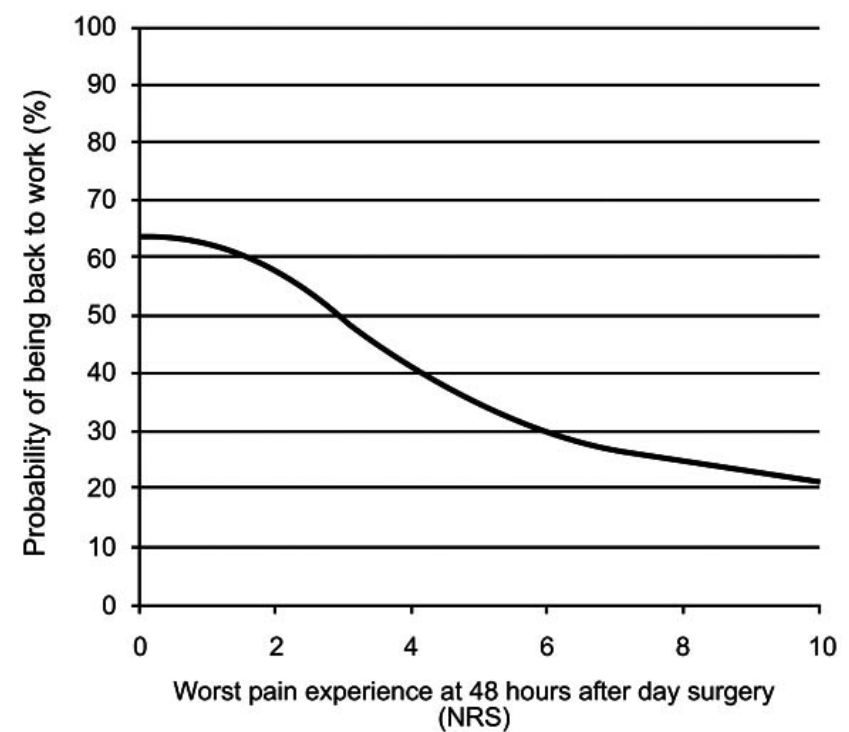

Fig. (4). Probability of returning to normal activity, seven days after day surgery, by applying logistic regression and spline function (Normal activity $=$ activity/work; i.e. housework or employment; calculations concerning being back to normal activity seven days after day surgery were performed by applying logistic regression and spline functions for worst pain experienced at 48 hours).

Table 2. Logistic Regression Analyses were Undertaken to Identify Predictors of Returning to Normal Activity at Seven Days

\begin{tabular}{|c|c|c|c|}
\hline Variable & $\boldsymbol{\beta}$ & $\mathbf{S E}$ & $\mathbf{P}$ \\
\hline \hline Constant & 4.33901 & 0.87352 & \\
\hline Interference work at T1 & -0.31460 & 0.06429 & 0.0000 \\
\hline Return to normal activity at T1 & -1.60344 & 0.47975 & 0.0008 \\
\hline
\end{tabular}

Interference work at T1 =Pain's interference with work at 48 hours after day surgery; Return to normal activity at $\mathrm{T} 1=$ Patients, who went back to work at 48 hours; Normal activity $=$ both employment and housework.

The discrimination is characterised as 'acceptable' for a discriminator or a predictor with an area under the ROC curve in the interval $0.7-0.8$, and as 'excellent' in the interval $0.8-0.9$ [41]. From the information in Table 2 we can calculate the probability of returning to normal activity seven days after surgery from the values for the variables interference with work at 48 hours and return to normal activity at 48 hours. Based on the assumption that a patient had not returned to normal activity at 48 hours and rating pain's interference with normal activity at NRS 7 for the variable normal activity at 48 hours, the probability of returning to normal activity at seven days is $26 \%$. Restricting the analysis to those aged 64 and younger $(n=230)$, in order to focus on patients who were probably gainfully employed, yielded a significant correlation between reported worst pain at 48 hours and return to normal activity after seven days ( $\mathrm{p}=0.001$, Pitman's test) [39]. This indicates that the more severe the reported pain at 48 hours, the greater the risk that the patient will be unable to resume normal activity within one week.

\section{DISCUSSION, LIMITATIONS AND RECOMMENDAT- IONS FOR FUTURE PRACTICE}

The main finding in this study is the extensive prevalence of pain after day surgery. Of the patients who answered the BPI-SF, $55 \%$ reported pain (NRS $\geq 4$ ) at 48 hours, $43 \%$ at seven days, and $34 \%$ at three months. The prevalence of worst pain (NRS $\geq 4$ ) was similar to that in previous studies using the BPI-SF for assessment during the first three days [4], or up to seven days [5] after day surgery. Pain is, as with other symptom experience, an interaction between perceptions of symptom, evaluation of the symptom and the response to the symptom, according to SMT [22]. Another result in this study was the extent of pain's interference with daily function, especially interference with work at seven days. This supports the relational statement in the SMT, that symptom experiences interact with outcomes such as functional status [22]. That pain at NRS $\geq 4$ apparently interferes with a patient's function has been reported earlier [42]. The incidence of patients whose pain interfered with work at 48 hours in this study is in agreement with Kemper et al. [4] and the corresponding incidence at seven days by Beauregard et al. [5]. When it comes to the ranking of the most affected factors, i.e. work, in daily function, the results of this study are consistent with previous research $[4,5]$.

The findings concerning inability to return to normal activities were also important and, to some extent, comparable with those by Horvath [20], who defined a dimension of recovery by patients' return to their usual activities and routines. Only $57 \%$ of the patients had returned to their usual activities six days after surgery. Furthermore, although patients were often independent when it came to basic activities of daily living, it was not unusual that two to three additional days were required to resume activities associated with role function, such as working outside the home. Gudex et al. [1] found that day surgery patients worked fewer hours per week one month following surgery. These results suggest that patients' ability to return to normal activities following day surgery is far more limited than was previously thought, but verification is required, particularly through studies of postoperative periods exceeding one month.

We do not know why $26.2 \%$ of the patients $(n=78)$ did not respond to the question of the use of pain medication at 48 hours. However, we do know that 55\% $(\mathrm{n}=230)$ reported pain $\geq 4$. Both Kemper [4] and Beauregard et a $l$ [5] found that medication use was low despite pain being rated as moderate to severe. None of these studies proceeded beyond seven postoperative days. Their findings were disquieting however, considering the risk of developing long-term pain. Residual pain lasting for more than three to six months after surgery constitutes a risk for persistent postsurgical pain [43]

It is known that acute postoperative pain is followed by residual pain in $10-50 \%$ of inpatients after large and 
complex operations, for example thorax surgery [19]. In the present study the patients had less complex surgery performed as day surgery. Despite this $8.7 \%(n=26)$ of the patients who participated in the study reported pain NRS $\geq 4$ at three months. This underlines the importance of the perioperative nurse being aware of risk factors i.e. VAS $\geq 4$ in the Post Anesthesia Care Unit, in order to be able to take preventive action [7]. A multimodal and aggressive perioperative analgesic regimen, including early therapy for postoperative pain in order to avoid provoking a residual pain state is needed [19].

The results of this study raise the question of whether improved pain management during the first 48 hours might make it possible for the patient to return to normal activity more quickly. It also highlights the importance of taking the components of symptom management strategies such as, take home packets of analgesia and information about the importance of pain treatment, into account when assessing outcome [22]. However, the varying analgesia regimens, which were dependent on the individual physicians' prescriptions and different types of anesthesia make it impossible to know how the findings are affected by this unknown variance in analgesia provision. Moreover, some patients may well not have taken the prescribed medication because they felt it was ineffective or fear of taking drugs. Therefore it is not possible to regard this as a non-adherence issue, described in the SMT as a critical factor, within the patient's control and which affects the outcome of an intervention [22].

Our findings have implications for preventing and managing pain at home following day surgery. Interventions to help patients handle their recovery period better must be based on evidence-based knowledge about the trajectory of pain after day surgery.

The majority of the patients responded after 48 hours, seven days and three months, respectively, which could be regarded as strength of the study. However, the internal attrition rate for scored worst pain at three months is a limitation. The fact that the three-month questionnaire was sent by mail may have affected the response rate negatively, since personal contact with respondents yields a higher response rate [44]. The internal response rate may also have been affected because patients no longer suffering any discomforts related to surgery may have been unmotivated. The authors of a similar study measuring pain up to one month following surgery [1], with a response rate of $27 \%$, expressed the opinion that the low response rate may serve as a reminder of the difficulties in recruiting sufficiently large patient samples. However, as we are unaware of any studies assessing pain as long as three months following day surgery, it is difficult to ascertain why we got an internal attrition rate at that time-point in this study. It is possible that the patients who reported pain at three months, suffered from this pain even before the day surgery. However, taking a history of prior pain was not routine at the day surgery ward and unfortunately this was not obtained in this study. All participants were, however, informed that all questions referred to surgery-related pain.

If, when the patients were reminded to respond, they stated that they did not remember their pain, they were informed to exclude this question in their response.
However, when recall of pain intensity (3-14 days) was evaluated compared with the actual pain recorded at this time, no significant difference was found [45-47]. We chose not to analyse the relationship between patients' perception of pain and types of surgery because it was not our purpose. Moreover, doing so would not have been meaningful, since the constituent group size would have been too small to generate any generalisable results.

Perioperative nurses need to be aware of risk factors, such as severe pain in the Post Anesthesia Care Unit, in order to take preventive action, such as pain relief. Knowledge about patients' pain duration, pain interference with daily function and general activities following day surgery is essential for the perioperative nurse to help optimise performance and provide good care.

It also highlights the need for nursing education to emphasise the importance of powerful pain relief and the giving of sufficient information to the patient. These issues can have serious consequences for long-term pain development and the ability to return to normal activities. Nurses need such knowledge in order to provide the professional support that patients ask for.

Future research should continue to longitudinally map the pain experience and the ability to return to normal activity in different groups of patients.

\section{CONCLUSIONS}

In summary this paper suggests that:

1) The proportion of pain on NRS pain $(\geq 4)$ after day surgery may exceed $50 \%$ after 48 hours, $40 \%$ at seven days and $30 \%$ at three months after surgery.

2) Pain particularly affects the variables: general activity, normal work and the ability to walk at 48 hours and seven days, after which its effect may subside.

3) There may be a significant correlation between worst pain at 48 hours and return to normal activity within seven days.

4) There may be a risk that patients can not return to normal activities within seven days because of worst pain experience at 48 hours after day surgery.

\section{REFERENCES}

[1] Gudex C, Sorensen J, Clausen I. Day surgery for gynaecological laparoscopy: clinical results from an RCT Ambul Surg 2006; 12(4): 151-7.

[2] Jarrett PEM. The developement of ambulatory surgery and future challenges. London: The International Association for Ambul Surg (IAAS) 2006.

[3] Rosén H, Lauzon Clabo LM, Mårtensson L. Symptoms following day surgery: a review of the literature. J Adv Periop Care 2009; 4(1): 9-20.

[4] Kemper JA. Pain management of older adults after discharge from outpatient surgery. Pain Manage Nurs 2002; 3(5): 141-3.

[5] Beauregard L, Pomp A, Choiniere M. Severity and impact of pain after day-surgery. Can J Anaesth 1998; 45(4): 304-11.

[6] Juarez G, Cullinane CA, Borneman T, et al. Management of pain and nausea in outpatient surgery. Pain Manage Nurs 2005; 6(4) 175-81.

[7] Pavlin DJ, Chen C, Penaloza DA, Buckley FP. A survey of pain and other symptoms that affect the recovery process after discharge from an ambulatory surgery unit. J Clin Anesth 2004; 16(3): 200-6. 
[8] Allard N. Day surgery and recovery in women with a suspicious breast lesion: evaluation of a psychoeducational nursing intervention. Can Oncol Nurs J 2006; 16(3): 137-44.

[9] Mattila K, Toivonen J, Janhunen L, Rosenberg PH, Hynynen M. Postdischarge symptoms after ambulatory surgery: first-week incidence, intensity, and risk factors. Anesth Analg 2005; 101(6): 1643-50.

[10] Rawal, Allvin R, Amilon A, Ohlsson T, Hallen J. Postoperative Analgesia at Home After Ambulatory Hand Surgery: A Controlled Comparison of Tramadol, Metamizol, and Paracetamol. Anesth Analg 2001; 92(2): 345-51.

[11] Erkal S. Patients' experiences at home after day case cystoscopy. J Clin Nurs 2007; 16(6): 1118-24.

[12] Pfisterer M, Ernst EM, Hirlekar G, et al. Post-operative nausea and vomiting in patients undergoing day-case surgery: an international, observational study. Ambul Surg 2001; 9(1): 13-8.

[13] Breivik H, Stubhaug A. Management of acute postoperative pain: still a long way to go! Pain 2008; 137(2): 233-4.

[14] Coll AM, Ameen J. Profiles of pain after day surgery: patients' experiences of three different operation types. J Adv Nurs 2006; 53(2): 178-87

[15] Tysome JR, Padgham ND. A comparative study of patient satisfaction with day case and in-patient major ear surgery. J Laryngol Otol 2006; 120(8): 670-5.

[16] Chung F, Assmann N. Car accidents after ambulatory surgery in patients without an escort. Anesth Analg 2008; 106(3): 817-20, table of contents.

[17] Cox H, O'Connell B. Recovery from gynaecological day surgery: are we underestimating the process. Ambul Surg 2003; 10(3): 11421.

[18] Watt-Watson J, Chung F, Chan VW, McGillion M. Pain management following discharge after ambulatory same-day surgery. J Nurs Manag 2004; 12(3): 153-61.

[19] Kehlet H, Jensen TS, Woolf CJ. Persistent postsurgical pain: risk factors and prevention. Lancet 2006; 367(9522): 1618-25.

[20] Horvath KJ. Postoperative recovery at home after ambulatory gynecologic laparoscopic surgery. J Perianesth Nurs 2003; 18(5): 324-34.

[21] Brattwall M, Stomberg MW, Rawal N, Segerdahl M, Houltz E, Jakobsson J. Patient assessed health profile: a six-month quality of life questionnaire survey after day surgery. Scand J Public Health 2010; 38(6): 574-9.

[22] Humphreys JA, Lee K, Carrieri-Kohlman V, et al. Theory of Symptom Management New York: Springer Publishing Company 2008.

[23] Melzack R. Pain and the neuromatrix in the brain. J Dent Educ 2001; 65(12): 1378-82.

[24] Bandyopadhyay M, Markovic M, Manderson L. Women's perspectives of pain following day surgery in Australia. Aust J Adv Nurs 2007; 24(4): 19-23.

[25] Meyer R, Ringkamp M, Campell J RS. Peripheral mechanisms of cutaneous nociception. In: Wall PD, Melzack R, McMahon SB, Koltzenburg M, Ed. Wall PD, Melzack R, Textbook of pain. 5 ed. Philadelphia: Elsevier/Churchill Livingstone 2006; 3-32.

[26] Cleeland CS. The Brief Pain Inventory User Guide PDF [cited 2008 December]; Available from: http://www.mdanderson.org/ education-and-research/departments-programs-and-labs/department s-and-divisions/symptom-research/symptom-assessment-tools/BPI_ UserGuide.pdf

[27] Flor H, Turk D. Cognitive and learning aspects. In: McMahon S, Kolzenburg M, Ed. Wall PD, Melzack R, Textbook of pain. 5 ed. Philadelphia: ELSEVIER Churchill Livingstone 2006; 241-258.
[28] Bergman B: Lung Division, Sahlgrenska University Hospital, Gothenburg. From the Brief Pain Inventory - Short Form, with the permission of Charles C. Cleeland, Ph.D., Pain Reseach Group, Dept. of Neurology, University of Wisconsin, Madison, In Idvall E. Quality indictors within nursing (Kvalitetsindikatorer inom omvårdnad). 2007 [cited 2009 March 2009]; Available from: http: //www.gothiaforlag.se/gothia/upload/files/digitala bilagor/7b_Canc errel_smarta_smartformularBPI_SF.pdf

[29] Idvall E, ed. Kvalitetsindikatorer inom omvårdnad. 5 ed. Stockholm: Gothia 2009.

[30] Hendrick P, Milosavljevic S, Bell M, et al. Does physical activity change predict functional recovery in low back pain? Protocol for a prospective cohort study. BMC Musculoskeletal Disorders 2009; 10(1): 136 .

[31] Lawrence K, McWhinnie D, Goodwin A, et al. Randomised controlled trial of laparoscopic versus open repair of inguinal hernia: early results. BMJ 1995; 311(7011): 981-5.

[32] Nutley MT, Mulloy RH, Hagen N. Minimal postoperative pain using properitoneal nontension sutured repair of direct inguinal hernias. Am J Surg 2006; 191(4): 479-82.

[33] Mendoza T, Mayne T, Rublee D, Cleeland C. Reliability and validity of a modified Brief Pain Inventory short form in patients with osteoarthritis. Eur J Pain 2006; 10(4): 353-61.

[34] Cleeland CS, Ryan KM. Pain assessment: global use of the Brief Pain Inventory. Ann Acad Med Singapore 1994; 23(2): 129-38.

[35] Keller S, Bann CM, Dodd SL, Schein J, Mendoza TR, Cleeland $\mathrm{CS}$. Validity of the brief pain inventory for use in documenting the outcomes of patients with noncancer pain. Clin J Pain 2004; 20(5): 309-18.

[36] Mendoza TR, Chen C, Brugger A, et al. The utility and validity of the modified brief pain inventory in a multiple-dose postoperative analgesic trial. Clin J Pain 2004; 20(5): 357-62.

[37] Klepstad P, Loge JH, Borchgrevink PC, Mendoza TR, Cleeland $\mathrm{CS}$, Kaasa S. The Norwegian brief pain inventory questionnaire: translation and validation in cancer pain patients. J Pain Symptom Manage 2002; 24(5): 517-25.

[38] Atkinson TM, Mendoza TR, Sit L, et al. The Brief Pain Inventory and Its "Pain At Its Worst in the Last 24 Hours" Item: Clinical Trial Endpoint Considerations. Pain Med 2020; 11:337-46.

[39] Good P. Permutation Test A Practical Guid to Resampling Methods for Testing Hypotheses. Berlin: Springer 2000.

[40] Odén A, Wedel H. Argument for Fishers permutation test: Annals of Statistics 1975: 3(2): 518-520.

[41] Hosmer D, Lemeshow S. Applied Logistic Regression. New York: John Wiley \& Sons 2000.

[42] Serlin RC, Mendoza TR, Nakamura Y, Edwards KR, Cleeland CS When is cancer pain mild, moderate or severe? Grading pain severity by its interference with function. Pain 1995; 61(2): 277-84.

[43] IASP. Pain terms: a list with definitions and notes on usage. Recommended by the IASP Subcommittee on Taxonomy. Pain 1979; 6(3): 249.

[44] Polit D, Beck C. Nursing research measuring and methods. Fhiladelphia: Lippincott Williams \& Wilkins 2004.

[45] Breme K, Altmeppen J, Taeger K. How reliable is our memory for acute postoperative pain. Anaesthesist 2000; 49(1): 18-24.

[46] Terry R, Brodie E, Niven CA. Exploring the phenomenology of memory for pain: is previously experienced acute pain consciously remembered or simply known? J Pain 2007; 8(6): 467-75.

[47] Terry R, Niven C, Brodie E, Jones R, Prowse M. An exploration of the relationship between anxiety, expectations and memory for postoperative pain. Acute Pain 2007; 9(3): 135-43.

Received: March 22, 2011

Revised: May 11, 2011

Accepted: May 12, 2011

(C) Rosén et al.; Licensee Bentham Open.

This is an open access article licensed under the terms of the Creative Commons Attribution Non-Commercial License (http://creativecommons.org/licenses/ by-nc/3.0/) which permits unrestricted, non-commercial use, distribution and reproduction in any medium, provided the work is properly cited. 